\title{
Crescimento e produtividade de plantas de tomateiro em cultivo protegido sob alta densidade e desfolhamento
}

\author{
Growth and fruit yield of greenhouse tomato plants under high plant density and defoliation
}

\author{
Jerônimo Luiz Andriolo ${ }^{1}$ Maria Carolina Grigoletto Espindola Rodrigo Godoi ${ }^{2}$ Orcial Ceolin Bortolotto $^{3}$ \\ Gean Lopes da $\mathrm{Luz}^{3}$
}

\section{- NOTA -}

RESUMO

\begin{abstract}
$O$ objetivo do trabalho foi determinar o efeito do aumento da densidade de plantas combinada com desfolhamento sobre o crescimento e a produtividade do tomateiro cultivado no solo em ambiente protegido. Os tratamentos consistiram de 3,3 (T1), 6,7 (T2) e 10,0 (T3) plantas $m^{-2}$. Em T1, três folhas por simpódio foram mantidas em todas as plantas. Em T2, em cada duas plantas consecutivas dentro da fileira, na primeira planta uma folha foi mantida no primeiro simpódio, enquanto na segunda planta duas folhas foram mantidas no simpódio de mesma ordem. No segundo simpódio, duas e uma folha foram mantidas, inversamente em relação ao simpódio anterior, $e$ assim sucessivamente durante o crescimento da cultura, até o final dos experimentos. Em T3, somente uma folha por simpódio foi mantida em cada planta. $O$ número de folhas $e$ de frutos foi contado e a massa fresca e seca dos frutos maduros foi determinada. $O$ número de folhas e de frutos foi similar entre os tratamentos no outono. Na primavera, o número de frutos foi mais elevado nas plantas de T2. A produtividade de frutos foi mais elevada em T2, nos cultivos de outono e de primavera. Na produção comercial dessa cultura conduzida no solo em ambiente protegido, a densidade de plantas com o desfolhamento testado em T2 pode ser empregada para maximizar a produtividade de frutos.
\end{abstract}

Palavras-chave: Lycopersicon esculentum, desenvolvimento, massa seca, cultivo protegido.

\begin{abstract}
The objective of this study was to determine the effect of plant density combined with defoliation on growth and fruit yield of greenhouse tomato plants grown in soil. Treatments consisted of 3.3 (T1), 6.7 (T2) and 10.0 (T3) plants $m^{-2}$. In T1, three leaves per sympod were left. In T2, for each two plants within a row, on the first plant one leaf was kept in the first sympod, whereas on the second plant two leaves were kept in the sympod of the same order. In the second sympod, two and one leaves were kept, inversely from the preceding one, and so on during the growth of the crop. In T3, only one leaf per sympod was kept. The number of leaves, trusses and fruits was counted, and fresh and dry mass of ripe fruits was determined. The number of leaves and fruits was similar among treatments in autumn. In spring, it was higher on $T 2$ plants. Fruit yield was higher on T2 plants in both experiments. For commercial production of this crop grown in soil under protected cultivation, the plant density and defoliation procedure tested in T2 might be used to increase fruit yield.
\end{abstract}

Key words: Lycopersicon esculentum, plant development, dry mass, greenhouse.

A produtividade de frutos do tomateiro depende do número de frutos fixados e da disponibilidade de assimilados para sustentar seu

${ }^{1}$ Engenheiro Agrônomo, Doutor, Professor Titular, Departamento de Fitotecnia, Universidade Federal de Santa Maria (UFSM), 97105-900, Santa Maria, RS. E-mail: andriolo@smail.ufsm.br. Autor para correspondência.

${ }^{2}$ Acadêmico do Curso de Agronomia da UFSM, bolsista do Programa de Iniciação Científica (PROBIC), Fundação de Amparo a Pesquisa do Rio Grande do Sul (FAPERGS).

${ }^{4}$ Acadêmico do Curso de Agronomia da UFSM, bolsista do Programa de Iniciação Científica (PIBIC), Conselho Nacional de Pesquisa (CNPq). 
crescimento (BERTIN, 1995; HEUVELINK, 1996). Na região Sul do Brasil, os valores da fração da massa seca nos frutos (FMSF) situam-se entre $40 \%$ e $50 \%$ (ANDRIOLO \& FALCÃO, 2000), abaixo daqueles citados em outros países, da ordem de 60\% (NUEZ, 1995; HEUVELINK, 1996; CTIFL, 1995). A poda de folhas é uma prática que tem sido sugerida para aumentar a FMSF nos frutos de plantas de tomateiro (GARBI et al., 1998). O desfolhamento implica redução do IAF. Consequientemente, a densidade de plantas desfolhadas poderia ser aumentada, até restabelecer o IAF ótimo para a cultura. A maior densidade de plantas aumentaria o número de frutos e a produtividade. O objetivo do trabalho foi testar a hipótese segundo a qual uma maior densidade de plantas de tomateiro, sem alterar o número de folhas por unidade de área de solo, poderia induzir um aumento no número de frutos e na produtividade.

Dois experimentos foram conduzidos na UFSM, no outono e na primavera de 2001, no interior de uma estufa de polietileno de $500 \mathrm{~m}^{2}$. Sementes do híbrido Monte Carlo foram semeadas em 15 de fevereiro e 04 de julho, com plantio em 29 de março e 9 de agosto de 2001, respectivamente, nos experimentos de outono e de primavera. $\mathrm{O}$ plantio foi feito no solo, em fileiras distanciadas de $1,0 \mathrm{~m}$, e as plantas tutoradas verticalmente através de fitas plásticas, com apenas uma haste por planta. O manejo da cultura foi efetuado de acordo com as recomendações para o cultivo dessa espécie em ambiente protegido (LOPES \& STRIPARI, 1998).
Foram comparadas três densidades de plantas combinadas com desfolhamento, mantendose similar o número de folhas por unidade de área de solo. As densidades foram de 3,3; 6,7 e 10,0 plantas $\mathrm{m}^{-2}$, nos tratamentos T1, T2 e T3, respectivamente. Em T1, três folhas por simpódio foram mantidas em todas as plantas. Em T2, em cada duas plantas consecutivas dentro da fileira, na primeira planta uma folha foi mantida no primeiro simpódio, enquanto, na segunda planta, duas folhas foram mantidas no simpódio de mesma ordem. No segundo simpódio, duas e uma folha foram mantidas, inversamente em relação ao simpódio anterior, e assim sucessivamente durante o crescimento da cultura, até o final dos experimentos. Em T3, somente uma folha por simpódio foi mantida em cada planta. $\mathrm{O}$ esquema experimental empregado foi de blocos casualizados, com quatro repetições, e uma fileira por parcela de $40 \mathrm{~m}^{2}$. Os frutos maduros foram colhidos e contados duas vezes por semana, determinando-se a seguir a massa fresca e a massa seca após secagem em estufa de circulação forçada de ar, a $60^{\circ} \mathrm{C}$, até massa constante. Os experimentos foram encerrados aos 158 e 147 dias após o plantio (DAP), respectivamente no outono e na primavera.

O número de folhas foi similar entre os tratamentos no outono, com média de 82 folhas $\mathrm{m}^{-2}$ (Tabela 1). Na primavera, foi similar em T1 e T2, com média de 87,5 folhas $\mathrm{m}^{-2}$ e inferior em T3, com 77 folhas $\mathrm{m}^{-2}$. O número de inflorescências nas plantas de T2 e T3 variou por um fator de 1,7 e 2,4 no outono e de 1,8 e 2,1 na primavera, respectivamente, em relação ao T1. O número de frutos foi similar nos três

Tabela 1 - Número de folhas, inflorescências e frutos e massa fresca e seca de frutos de plantas de tomateiro ao final dos experimentos de outono e de primavera. Santa Maria, UFSM, 2001.

\begin{tabular}{|c|c|c|c|c|c|}
\hline & \multicolumn{3}{|c|}{ Número $\left(\mathrm{m}^{-2}\right)$} & \multicolumn{2}{|c|}{$\operatorname{Massa}\left(\mathrm{g} \mathrm{m}^{-2}\right)$} \\
\hline & Folhas & Inflorescências & Frutos & Seca & Fresca \\
\hline \multicolumn{6}{|l|}{ Outono } \\
\hline $\mathrm{T} 1$ & $84 \mathrm{a}^{*}$ & $27 \mathrm{c}$ & $41 \mathrm{a}$ & 95,9 a & $5.225,4 \mathrm{~b}$ \\
\hline $\mathrm{T} 2$ & $82 \mathrm{a}$ & $47 \mathrm{~b}$ & $40 \mathrm{a}$ & $105,0 \mathrm{a}$ & $7.105,5 \mathrm{a}$ \\
\hline $\mathrm{T} 3$ & $80 \mathrm{a}$ & $65 \mathrm{a}$ & $41 \mathrm{a}$ & $111,3 \mathrm{a}$ & $5.327,8$ b \\
\hline Média & 82 & 46 & 41 & 104,1 & $5.886,2$ \\
\hline $\mathrm{CV}(\%)$ & 4,77 & 12,52 & 20,01 & 15,05 & 7,99 \\
\hline \multicolumn{6}{|c|}{ Primavera } \\
\hline $\mathrm{T} 1$ & $88 \mathrm{a}$ & $26 \mathrm{c}$ & $61 \mathrm{ab}$ & $304,1 \mathrm{~b}$ & $10.733,1 \mathrm{a}$ \\
\hline $\mathrm{T} 2$ & $87 \mathrm{a}$ & $47 \mathrm{~b}$ & $74 \mathrm{a}$ & $363,4 \mathrm{a}$ & $12.277,0 \mathrm{a}$ \\
\hline $\mathrm{T} 3$ & $77 \mathrm{~b}$ & $57 \mathrm{a}$ & $53 \mathrm{~b}$ & $287,4 \mathrm{~b}$ & $8.101,1 \mathrm{~b}$ \\
\hline Média & 84 & 43 & 62,7 & 318,3 & $10.370,4$ \\
\hline $\mathrm{CV}(\%)$ & 3,20 & 8,58 & 17,17 & 9,59 & 11,01 \\
\hline
\end{tabular}

*Médias não seguidas pela mesma letra na coluna diferem significativamente pelo teste de Duncan em nível de $5 \%$ de probabilidade de erro. 
tratamentos no outono, com média de 41 frutos $\mathrm{m}^{-2}$. Na primavera, foi similar em T1 e T2, com média de 67 frutos $\mathrm{m}^{-2} \mathrm{e}$ inferior em T3, com 53 frutos $\mathrm{m}^{-2}$. A massa seca de frutos foi mais elevada em T3 no outono, sem diferenças significativas entre os tratamentos. $\mathrm{Na}$ primavera, foi mais elevada em T2. A produtividade de frutos atingiu médias mais elevadas em T2, em ambos os experimentos. Na primavera, o valor mais baixo foi observado nas plantas de T3.

Os tratamentos permitiram aumentar o número de inflorescências no experimento de outono por um fator de 1,7 e 2,4 em T2 e T3, respectivamente, mas nenhum efeito significativo foi observado no número de frutos fixados. Esse fato pode ser explicado pela disponibilidade de assimilados, uma vez que após os 110 DAP os níveis de radiação solar passaram a se situar próximos do limite trófico da cultura. $\mathrm{Na}$ primavera, a radiação solar não foi limitante ao crescimento, podendo explicar o maior número de frutos fixados nas plantas de T2. Entretanto, essa variável diminuiu em T3, o que pode ser atribuído à competição pelos assimilados entre os drenos e as fontes, reduzindo o crescimento vegetativo da planta inteira (HEUVELINK \& BUISKOOL, 1995). O trabalho hipotetizava atingir maior crescimento e produtividade no tratamento T3, uma vez que o número de folhas foi mantido similar entre os tratamentos. Entretanto, no outono, o crescimento dos frutos foi similar nos três tratamentos e, na primavera, foi mais baixo nas plantas de T3. Esses resultados podem ser explicados pelos efeitos do ambiente, tanto sobre a produção como sobre o transporte dos assimilados entre as fontes e os drenos. No outono, as temperaturas do ar no decorrer do nictêmero situaram-se, em sua maior parte, abaixo do valores mais favoráveis ao transporte dos assimilados em plantas de tomateiro (ADAMS et al., 2001a,b). Na primavera, os níveis de radiação solar estiveram acima do limite trófico e os valores das temperaturas do ar durante o nictêmero se situaram, em sua maior parte, dentro dos limites favoráveis ao transporte dos assimilados e o crescimento da planta. Nessas condições, o crescimento reduzido das plantas de $\mathrm{T} 3$ pode ser explicado pelo efeito negativo da força de dreno dos frutos sobre o crescimento e desenvolvimento do compartimento vegetativo da planta, especialmente o número de folhas e a área folhar, os quais influenciam a capacidade fotossintética da planta(KONING, 1994; HEUVELINK \& BUISKOOL, 1995).
Para efeito de produção comercial de frutos de tomateiro em cultivo protegido, os resultados indicam que a densidade de plantas de 6,7 plantas $\mathrm{m}^{-2}$, combinada com o desfolhamento praticado em T2, poderia ser empregada para maximizar a produtividade, sob condições ambientais não limitantes ao crescimento e desenvolvimento da cultura.

\section{REFERÊNCIASBIBLIOGRÁFICAS}

ADAMS, S.R. et al. Effect of temperature on the growth and development of tomato fruits. Annals of Botany, Oxford, v.88, p.864-877, 2001a.

ADAMS, S.R. et al. The impact of changing light levels and fruit load on the pattern of tomato yields. Journal of Horticultural Science \& Biotechnology, Ashford Kent, v.76, p.368-373, $2001 \mathrm{~b}$.

ANDRIOLO, J.L.; FALCÃO, L.L. Efeito da poda de folhas sobre a acumulação de matéria seca e sua repartição para os frutos do tomateiro cultivado em ambiente protegido. Revista Brasileira de Agrometeorologia, Santa Maria, v.8, p.7583, 2000.

BERTIN, N. Competition for assimilates and fruit position affect fruit set in indeterminate greenhouse tomato. Annals of Botany, Oxford, v.75, 55-65, 1995.

CTIFL, 1995. Maîtrise de la conduite climatique. Paris: Centre Technique Interprofessionel des Fruits e des Légumes, 1995. 127p.

GARBI C. et al. La defoliación del tomate induce aumentos de la biomassa foliar y del rendimento. In: REUNIÓN ARGENTINA DE FISIOLOGIA VEGETAL, 21., 1998, Buenos Aires, Argentina. Actas... Buenos Aires : Sociedad Argentina de Fisiologia Vegetal, 1998. p.154-155.

HEUVELINK, E. Tomato growth and yield: quantitative analysis and synthesis. 1996. 326f. Dissertation. Wageningen Agricultural University.

HEUVELINK, E.; BUISKOOL, R.P.M. Influence of sinksource interaction on dry matter production in tomato. Annals of Botany, Oxford, v.75, p.381-389, 1995.

KONING, A.N.M. de. Development and dry mass distribution in glasshouse tomato: a quantitative approach. 1994. 240f. Dissertation. Wageningen Agricultural University.

LOPES, M.C.; STRIPARI, P.C. A cultura do tomateiro. In: GOTP, R.; TIVELli, S.W. (Ed.). Produção de hortaliças em ambiente protegido. São Paulo : UNESP, 1998. $319 \mathrm{p}$.

NUEZ, F. El cultivo del tomate. Madrid : Mundi-Prensa, 1995. 793p. 